\title{
Autoimmune pancreatitis in Japan: overview and perspective
}

\author{
Tooru Shimosegawa $\cdot$ Atsushi Kanno
}

Received: 26 February 2009/Accepted: 26 February 2009/Published online: 18 April 2009

(C) Springer 2009

\begin{abstract}
Since the rediscovery and definition of autoimmune pancreatitis (AIP) by Yoshida et al. in 1995, the disease has been attracting attention because of its unique clinical features and practical issues. This disease shows very impressive imaging findings, serological changes, and characteristic histopathology. It occurs most commonly in elderly males with painless jaundice or mild abdominal pain; resemblance in imaging findings between AIP and pancreatobiliary cancers poses an important practical issue of differentiation. With increasing recognition of AIP and accumulation of cases, another important feature of this disease has been revealed, i.e., association of extrapancreatic organ involvements. Initially misunderstood because it can be accompanied by other autoimmune disorders, such as Sjögren's syndrome or primary sclerosing cholangitis (PSC), AIP is now known to be associated with unique types of sialadenitis and cholangitis distinct from Sjögren's syndrome or PSC. Now the concept of "IgG4related sclerosing disease" has become widely accepted and the list of organs involved continues to increase. With worldwide recognition, an emerging issue is the clinical definition of other possible types of autoimmune-related pancreatitis called "idiopathic duct-centric chronic pancreatitis (IDCP)" and "AIP with granulocyte epithelial lesion (GEL)" and their relation to AIP with lymphoplasmacytic sclerosing pancreatitis (LPSP). The time has arrived to establish clinical diagnostic criteria of AIP based on international consensus and to discuss regional and racial differences in the clinicopathological features of AIP. Consensus guidelines are also required for the ideal
\end{abstract}

T. Shimosegawa $(\bowtie) \cdot$ A. Kanno

Division of Gastroenterology, Tohoku University Graduate

School of Medicine, 1-1 Seiryo-machi, Aoba-ku, Sendai, Japan

e-mail: tshimosegawa@int3.med.tohoku.ac.jp use of steroids in the treatment of AIP to suppress recurrence efficiently with minimal side effects. There are many issues to be settled in AIP; international collaboration of experts in the pancreas field is necessary to clarify the entire picture of this unique and important disease.

Keywords Autoimmune pancreatitis - LPSP · IgG4 . IgG4-related sclerosing disease $\cdot$ Steroid therapy

\section{Preface}

Autoimmune pancreatitis is a newly recognized form of pancreatic disease, recently attracting worldwide attention. More than 10 years have passed since the landmark report on the case of an AIP patient by Yoshida et al. [1], but the concept of AIP is not yet well-established and is, in a sense, still emerging. In this review, the current understanding of AIP is reviewed and then the issues to be settled in the near future are discussed.

\section{History}

Pancreatitis which develops on the basis of immunity mechanisms was first described by Sarles et al. [2]. They reported the clinical and pathological findings of 10 patients with noncalcifying chronic pancreatitis which showed peculiar features, such as onset with obstructive jaundice, symptoms of fever, emaciation and dyspepsia, hypergammagloblinemia, and pathological findings of massive infiltration of inflammatory cells in the pancreas. After searching in vain for the causal germ, they concluded that "chronic inflammatory sclerosis of the pancreas" may be caused by a self-immunization phenomenon. It is 
uncertain whether the pancreatitis they reported coincides with AIP as we currently understand it, but this unique pancreatitis disappeared from the main stage of pancreatic clinical and research history for a while. Only a small number of case reports can be found before 1995 [1] that refer to pancreatitis in accompaniment with other immunerelated diseases such as Sjögren's syndrome and PSC [38]. Among them, one by Kawaguchi et al. [8] published in 1991 deserves special comment in that it pointed out the pancreatitis currently recognized as AIP and defined its pathological feature as lymphoplasmacytic sclerosing pancreatitis (LPSP). In 1992, the Japan Pancreas Society (JPS) launched an effort to establish the clinical criteria of chronic pancreatitis in Japan . In the process, the working committee noticed a unique pancreatitis characterized by diffuse narrowing of the main pancreatic duct (MPD) on endoscopic retrograde pancreatography (ERP) scans. The pancreatitis originally reported by Toki et al. [9] was described in marginal notes of the newly established JPS Criteria of Chronic Pancreatitis in 1995 as "duct-narrowing chronic pancreatitis", a chronic inflammation of the pancreas which may not fulfill the criteria of chronic pancreatitis [10]. This facilitated the recognition of unusual types of pancreatitis in Japan.

In 1995, Yoshida et al. reported a 68 year old female patient who developed obstructive jaundice and was diagnosed as having inoperable pancreatic cancer based on radiological findings of swollen pancreas and obstruction of the common bile duct [1]. Only exploratory laparotomy was performed but, soon afterwards, her jaundice remitted spontaneously. The patient showed significant diffuse narrowing of MPD with an irregular wall on ERP, and elevated serum IgG and positive anti-nuclear antibody (ANA). No malignant cells and only fibrotic change with lymphocytes were observed in the needle biopsy specimen of the pancreas. Considering the possibility of pancreatitis caused by autoimmune mechanism, she was treated by oral prednisolone resulting in a resolution of pancreas swelling and normalization of the MPD and serum IgG level as well as reduction in the ANA titer. The authors designated this unusual pancreatitis as "AIP" for the first time, and defined the disease with 11 items from the common clinical and laboratory findings of 10 cases that had been reported previously [2-8].

With an accumulation of similar cases in our country, the JPS issued the world's first diagnostic criteria of AIP in 2002 [11]. The criteria consisted of 3 items, (1) imaging findings, (2) serum findings and (3) pathological findings; diagnosis of AIP is made when more than 2 items, including the imaging findings as essential, are found. In the 2002 criteria, the length of main duct narrowing on ERP was defined as more than $1 / 3$ of the entire pancreas in order to avoid confusion with short segment narrowing or stenosis caused by pancreatic cancer. As a result, the 2002 criteria were diagnostic for typical diffuse type AIP but failed to diagnose atypical localized type AIP, which shows focal or segmental swelling of the pancreas and short segment MPD narrowing less than $1 / 3$ of the entire pancreas. The JPS worked together with the Research Committee of Intractable Pancreatic Diseases (RCIPD), supported by the Ministry of Health, Labor and Welfare of Japan, and revised the 2002 Criteria to improve the sensitivity to localized type AIP in 2006 (Table 1) [12, 13]. Major revisions were elimination of the dependency on the length of MPD narrowing and an incorporation of IgG4 in the serology criterion, a factor which had been recognized as a specific and highly sensitive marker of this disease since the report by Hamano et al. [14]. Another important revision was made in the definition of AIP in the preface of the criteria. A sentence appearing in the 2002 criteria, "AIP can be isolated or associated with Sjögren's syndrome or other immune-mediated disorders," was changed to the sentence, "Currently, it has been observed that AIP associates sclerosing cholangitis, sclerosing sialadenitis, and retroperitoneal fibrosis based on the accumulation of many AIP patients, suggesting that AIP may be a systemic disease," in the 2006 criteria. The change was made because sclerosing cholangitis and sialadenitis frequently associating with AIP had been recognized as distinct from PSC and Sjögren's syndrome, respectively. In addition, various other organ involvements had become widely recognized under the concept of "IgG4-related sclerosing disease" advocated by Kamisawa et al. [15-17].

The spread of knowledge on AIP in the world promoted the recognition of this disease not only in Asian countries but also in Western countries [18-22]. Recently, an increasing number of case reports have been made from outside of Japan, confirming that this disease exists beyond regions and races. With accumulation of international information on AIP, it is becoming clear that there are different types resembling AIP [23-25]. In addition, several other diagnostic criteria of AIP were proposed from several countries such as Korea [26], the US [27] and Italy [18]. Therefore, now is the time to seek international consensus for the clinicopathological understanding, diagnosis and treatment of AIP.

\section{Current understanding of AIP}

Epidemiology

The RCIPD of Japan carried out a nationwide survey on AIP in 2002 [28].

It estimated that 900 patients fulfilled the 2002 Japanese Criteria of AIP, an incidence of $0.71 / 100,000$ people. The 
Table 1 Japanese clinical diagnostic criteria of autoimmune pancreatitis 2006

1. Diffuse or segmental narrowing of the main pancreatic duct with irregular wall and diffuse or localized enlargement of the pancreas by imaging studies, such as abdominal ultrasonography (US), computed tomography (CT), and magnetic resonance imaging (MRI)

2. High serum $\gamma$-globulin, IgG, or IgG4, or the presence of autoantibodies, such as antinuclear antibodies and rheumatoid factor

3. Marked interlobular fibrosis and prominent infiltration of lymphocytes and plasma cells in the periductal area, occasionally with lymphoid follicles in the pancreas

Diagnosis of autoimmune pancreatitis is established when criterion 1, together with criterion 2 and/or 3, are fulfilled. However, it is necessary to exclude malignant diseases such as pancreatic or biliary cancers

number corresponds to roughly $2 \%$ of chronic pancreatitis patients in Japan whose number in 2002 was estimated to be 45,200 . The same survey revealed that there were nearly 800 patients who did not satisfy the criteria; the cases were atypical but considered to be autoimmune-based pancreatitis.

Recently, Nishimori et al. reviewed the 2002 data and characterized 181 AIP patients who met the Clinical Diagnostic Criteria of AIP 2006. According to the report [29], the male to female ratio was 2.77 , the peak age at onset was in the sixties and the patients older than 46 years old accounted for $96 \%$ of overall patients. In addition, 52\% of the patients showed diffuse narrowing of the entire MPD on ERP, $38 \%$ of the patients showed segmental narrowing of MPD longer than $1 / 3$ of the entire pancreas, while only $8 \%$ showed short segment narrowing less than $1 / 3$ of the entire length of the MPD. It is preliminary, but the recent nationwide survey by the RCIPD of Japan predicts that the number of AIP patients in 2007 increased to 3,000, up by 1,300 compared with the 2002 survey.

\section{Clinical symptoms}

There are no symptoms specific to AIP. According to the RCIPD search on the steroid responsive patients suspected of AIP [30], obstructive jaundice was found in $33 \%$ of patients, abdominal pain in $32 \%$, followed by back pain in $15 \%$, weight loss in $15 \%$, and appetite loss and general fatigue in $9 \%$ each. It is reported that $15 \%$ of patients were asymptomatic. Abdominal pain, if any, is usually mild to moderate and severe pain such as seen in acute pancreatitis is rare. Since AIP develops frequently in elderly males with painless obstructive jaundice, mild abdominal pain or nonspecific symptoms such as weight loss and appetite loss, careful differentiation between AIP and pancreatobiliary malignant diseases is a core issue in clinical practice.

\section{Imaging characteristics}

\section{Abdominal ultrasound, endoscopic US, intraductal US}

Abdominal ultrasound (US) is a simple noninvasive method for examining the pancreas not only for the diagnosis of AIP but for its response to steroid therapy. The US

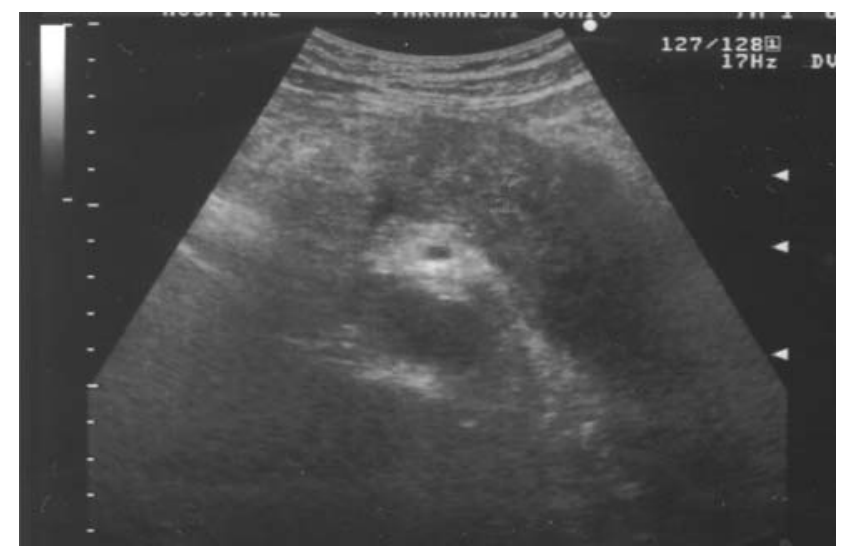

Fig. 1 US of AIP. The swollen pancreas shows "sausage-like" appearance with homogeneously low-echoic pattern [109]

imaging of typical AIP is a diffusely swollen pancreas with a homogenously hypoechoic pattern which associates occasionally with scattering of tiny bright spots. The imaging is called "sausage-like" from its appearance (Fig. 1) [31]. Atypical localized type AIP sometimes shows a hypoechoic tumor-like mass lesion with a relatively clear margin, making it very hard to discriminate from pancreatic cancer. Duct penetration signs, if present, favor the diagnosis of AIP. The endoscopic US (EUS) findings of AIP are essentially similar to abdominal US, though its higher resolution can provide clearer images of the involved area.

In addition to the characteristic imaging of the pancreas, US is helpful in detecting thickening of the wall of the biliary tract, the finding of sclerosing cholangitis seen in approximately $60 \%$ of AIP patients. The wall thickening is detected chiefly in the common bile duct, sometimes spreading to the gallbladder and even to the intrahepatic bile ducts [32]. Intraductal US (IDUS) shows that the thickened wall is due to thickening of the luminal-side hypoechoic layer, while the outer hyperechoic layer is preserved [33].

\section{Computed tomography}

Computed tomography (CT) identification of AIP is characterized by the delayed enhancement of the swollen pancreas on dynamic CT (Fig. 2a, b) [31-35]. Irrespective 
Fig. 2 Dynamic CT of AIP. The swollen pancreas shows delayed enhancement, which is characterized by gradual enhancement of the pancreatic parenchyma in delayed imaging (b) compared with the early imaging (a). The swollen pancreas shows a low density rim-like structure in the periphery of the pancreas called "capsule-like rim"

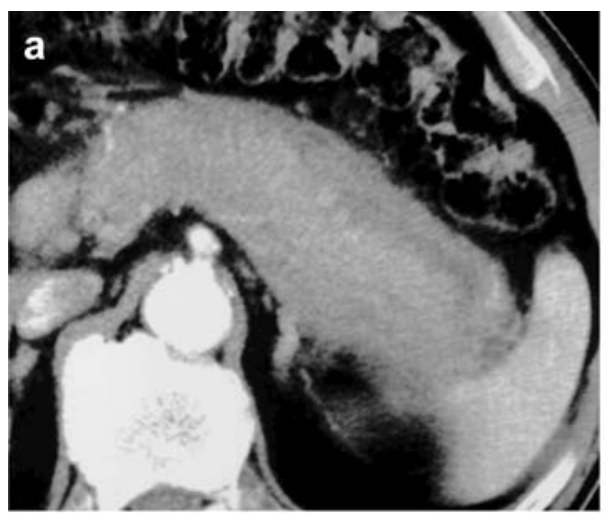

early

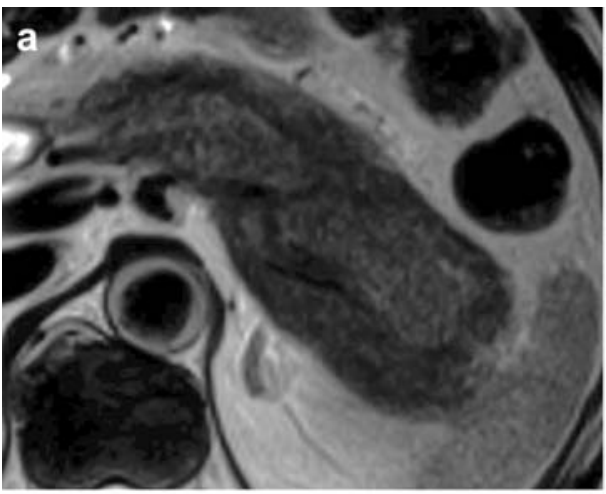

T2WI
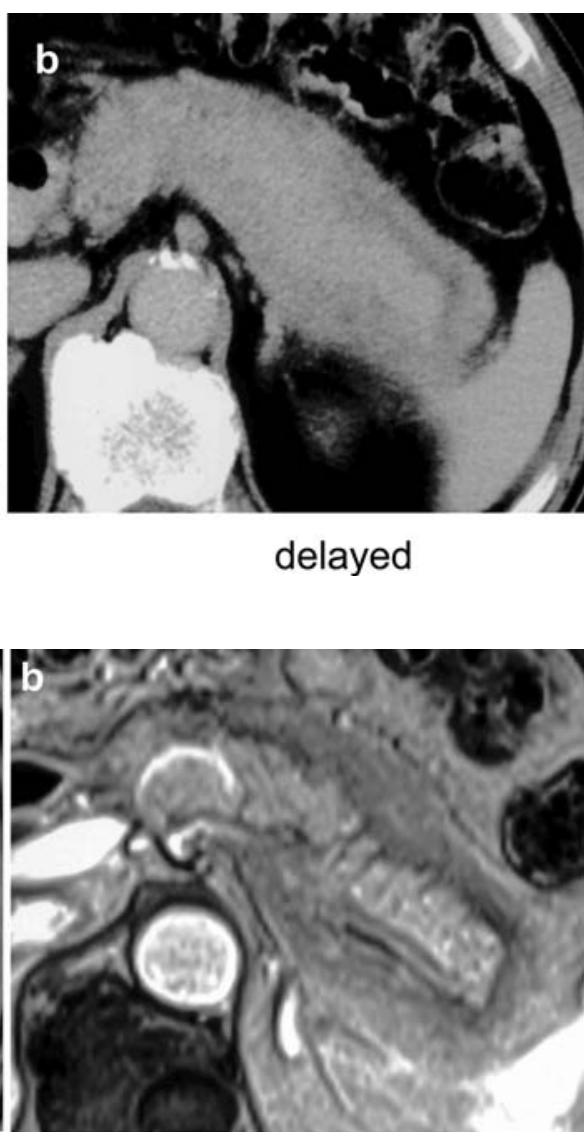

Gd of diffuse or localized enlargement of the pancreas, the involved area is seen as slightly low density compared with the uninvolved area in early images, with increases in density in delayed images. As a finding specific to AIP, patients occasionally show a low density rim-like structure surrounding the pancreas called a "capsule-like rim" which is also enhanced in a delayed manner on dynamic CT (Fig. 2a, b) [34]. The structure is considered to reflect fibrosis and inflammation involving the peripancreatic adipose tissue. If a capsule-like rim is found in the CT imaging, it strongly suggests a diagnosis of AIP and helps to rule out pancreatic cancer [34].

\section{Magnetic resonance imaging}

MR imaging of AIP shows swelling of the pancreas similar to that shown by other imaging modalities. The involved area typically shows a signal lower than the liver in T1-weighted images. The signal intensity in T2weighted images is variable depending on the amount of fibrosis (Fig. 3a) [31-35]. As in the case of CT, the characteristic finding of AIP is delayed enhancement of the involved area on dynamic magnetic resonance imaging (MRI). The "capsule-like rim" can be shown even in
T2-weighted MR images as a low signal structure which is enhanced in a delayed manner on dynamic MRI (Fig. 3a, b) [34]. MRCP is not suitable for the diagnosis of AIP due to unsatisfactory resolution for visualizing the narrowed MPD. However, the recently introduced 3-T superconducting MR unit may be a powerful tool to examine the response of MPD to steroids and for the surveillance of recurrence [31].

\section{Endoscopic retrograde cholangiopancreaticography}

The imaging most characteristic of AIP can be obtained by endoscopic retrograde cholangiopancreaticography (ERCP). Indeed, the peculiar finding of diffusely narrowed MPD led to establishment of the concept of AIP [1, 9]. Narrowing of the MPD is defined as different from obstruction and stenosis; in AIP, MPD with a smaller caliber than usual spans a certain range, showing irregularity of the wall (Fig. 4) [36-38]. In typical AIP, duct narrowing spans more than $1 / 3$ of the entire length of the MPD. Even in the case of short segment MPD narrowing, the upstream MPD usually does not show remarkable dilatation, a sign by which to discriminate pancreatic cancer (Fig. 5) [39, 40]. Up to $80 \%$ of AIP patients show 


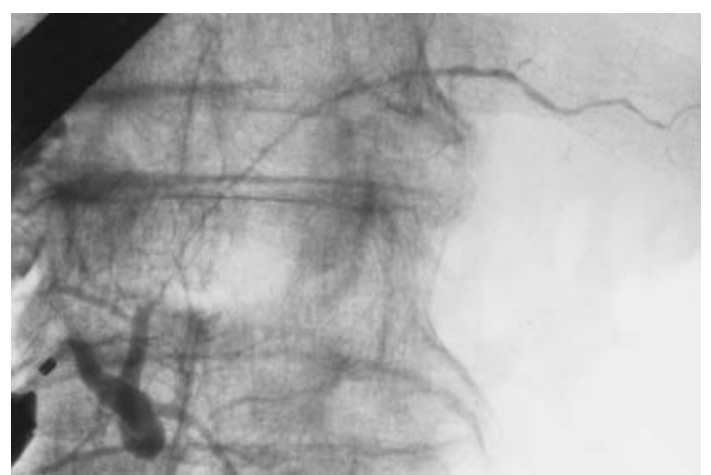

Fig. 4 ERP of diffuse type AIP. The main pancreatic duct (MPD) shows diffuse narrowing with an irregular wall [109]

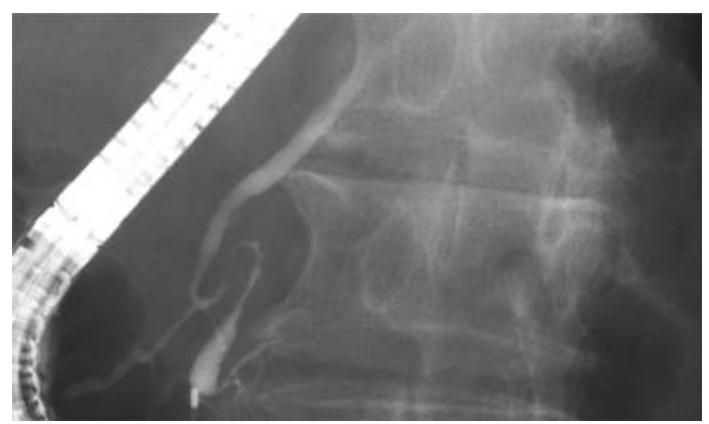

Fig. 5 ERP imaging of localized type AIP. The MPD narrows in a short segment in the pancreas head, but the upstream MPD does not show remarkable dilatation

biliary stenosis, most frequently seen in the lower part of the common bile duct, but also capable of occurring in any part of extra or intrahepatic biliary tract [36, 41-43].

\section{$\left[{ }^{18} \mathrm{~F}\right]$ fluorodeoxyglucose positron emission tomography and Ga-scintigraphy}

In AIP patients, FDG is taken up strongly in the involved area of the pancreas, but disappears quickly in response to steroid treatment [44]. Although $\left[{ }^{18} \mathrm{~F}\right]$ fluorodeoxyglucose positron emission tomography (FDG-PET) is unable to differentiate AIP from pancreatic cancer, because the latter also takes up FDG, showing a high SUVmax [45], this imaging modality is very useful in understanding the distribution of involved extrapancreatic organs such as salivary glands, pulmonary hilar lymph nodes, retroperitoneal fibrosis and prostate gland [46, 47]. The accumulation of FDG in extrapancreatic lesions also disappears promptly in response to steroid treatment (Fig. 6a, b) [48]. The resolution of Ga-scintigraphy is low compared with FDG-PET, but it can show extrapancreatic lesions such as swelling of lacrimal and salivary glands and pulmonary hilar lymph nodes [49].
Serum findings

\section{Immunoglobulins}

The Japanese Clinical Criteria of AIP 2006 employs serum $\gamma$-globulin $(\geqq 2.0 \mathrm{~g} / \mathrm{dl}), \quad \operatorname{IgG}(\geqq 1,800 \mathrm{mg} / \mathrm{dl})$ and $\mathrm{IgG} 4$ $(\geqq 135 \mathrm{mg} / \mathrm{dl}$ ) as the serum markers of AIP (Table 1) [12, 13]. The positive rates in AIP are 50-60, 60-80 and 68$92 \%$ for $\gamma$-globulin, $\operatorname{IgG}$ and $\operatorname{IgG} 4$, respectively [30, 50, 51]. Serum IgG4 is superior to $\operatorname{IgG}$ with a sensitivity of $86 \%$, a specificity of $96 \%$ and accuracy of $91 \%$ in differentiation of AIP from pancreatic cancer, compared to 69, 75 and $72 \%$ for IgG [52].

The value of serum IgG4 as a sensitive marker of AIP was established by Hamano et al. [14]. They reported initially that its sensitivity, specificity and accuracy for differentiating AIP from pancreatic cancer were 90.2, 97.5 and $95.0 \%$, respectively. In addition, elevation of serum IgG4 was specific to AIP and was not seen in other diseases such as chronic pancreatitis, PSC, Sjögren's syndrome and primary biliary cirrhosis (PBC), suggesting AIP as a distinct disease. In spite of its superiority as a marker, IgG4 is still not covered by the health insurance in Japan. As an alternative to IgG4, serum $\gamma$-globulin and IgG can be used to estimate disease activity, response to steroids and to predict recurrence [52]. Recently Ghazale et al. [53] reported that 13 out of 135 pancreatic cancer patients (10\%) showed slight elevation of serum IgG4 and therefore called attention to possible overconfidence in $\mathrm{IgG} 4$, as it is not a disease-specific marker.

\section{Antibodies}

Various antibodies appear in the sera of AIP patients. Representative examples include anti-lactoferrin antibody (ALF), anti-carbonic anhydrase II antibody (CA-II), ANA and Rheumatoid factor (RF) with the respective frequency of 75, 55, 60 and 20-30\% [51]. The Japanese Clinical Criteria 2006 employed ANA and RF as serum markers of AIP (Table 1). In differentiation from pancreatic cancer, the sensitivity, specificity and accuracy of ANA are 58, 79 and $67 \%$, while those of RF are 23, 94 and 54\%, respectively [52]. Although the diagnostic capacities of these factors are not satisfactory by themselves, a combination of ANA, RF and IgG is reported to increase the sensitivity to $91 \%$, specificity to $61 \%$ and accuracy to $78 \%$ [52].

SS-A (Ro) and SS-B (La) antibodies, markers of Sjögren's syndrome, are rarely seen in AIP patients, giving additional grounds for the idea that sclerosing sialadenitis seen in AIP patients is distinct from Sjögren's syndrome. Anti-mitochondria antibody (AMA), a specific marker of PBC, is also very rarely detected in AIP patients. It is reported that one fourth of AIP patients show a decrease in thyroid function and $34 \%$ and $17 \%$ of them are associated with 
Fig. 6 Whole-body FDG-PET imaging of a patient with AIP. FDG is taken up to the body and tail of the swollen pancreas, the large pseudotumor of the liver, the pulmonary hilar lymph nodes and to the salivary glands (a). It disappears shortly after starting steroid treatment (b)

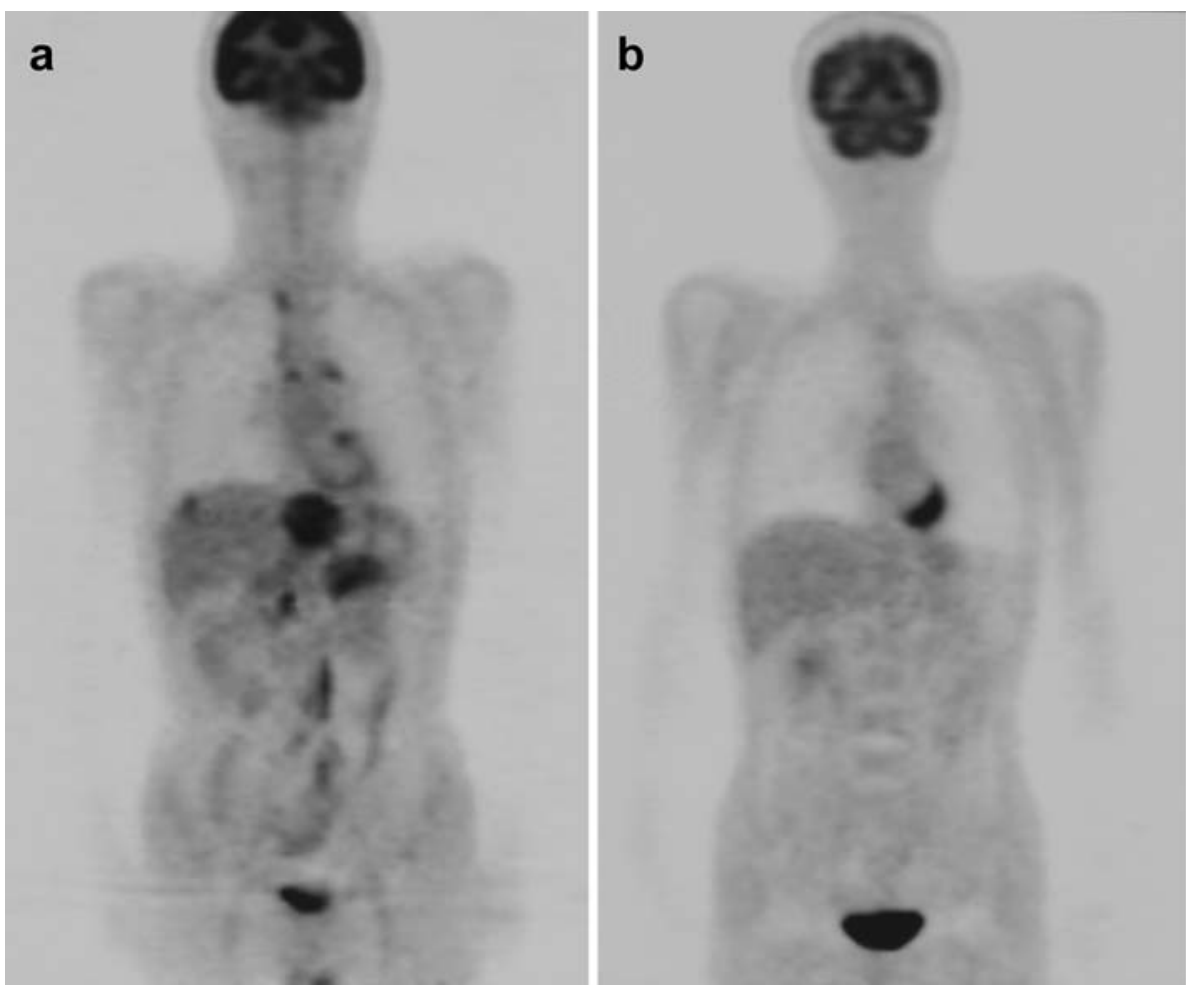

positive anti-thyroglobulin antibody and anti-thyroid peroxidase (TPO) antibody, respectively [54].

\section{Pathological findings}

The histopathological identification of AIP is defined by LPSP [8]. The diagnosis of AIP can be made solely with the histological finding of LPSP when large specimens are obtained for evaluation. The finding is characterized by strong fibrosis called "storiform fibrosis" with massive infiltration of lymphocytes and plasma cells and obliterating phlebitis (Fig. 7a) [55-57]. In most AIP cases, immunohistochemistry clearly demonstrates that plasma cells seen in the lesion are largely positive for IgG4 (Fig. 7b) [57-59]. However, caution is advised, in that infiltration of IgG4 positive cells is not specific to AIP but can be seen even in the lesions of pancreatic cancer and alcoholic chronic pancreatitis [58,60].

There are some reports, chiefly from Western countries, describing AIP with unique pathological features distinct from LPSP. The pathological finding of "IDCP" or "AIP with GEL" is characterized by massive infiltration of granulocytes in the pancreatic parenchyma and into the ductal epithelium [23-25, 55, 57, 58, 60]. AIP patients with IDCP or GEL are reported to be younger, equal to both sexes, short of IgG4 abnormality, and frequently complicated with inflammatory bowel diseases. It is possible that these patients may constitute a certain group of AIP, but the current international consensus of AIP is based on the pathological findings of LPSP [13, 27, 57, 61].
Exocrine and endocrine pancreatic function

Approximately $70 \%$ of AIP patients show exocrine and endocrine dysfunction [62]. According to the results of a 2002 nationwide survey of AIP by the RCIPD of Japan [63], 66.5\% of 167 patients who fulfilled the Japanese Criteria of AIP 2002 had diabetes mellitus (DM). According to the report, 52\% of them developed DM simultaneously at the onset of AIP, while 33\% had manifested DM before the onset. Control of DM was improved by steroid therapy in $55 \%$ and $36 \%$ of these patients, respectively. Fewer than $20 \%$ of patients showed deterioration in the control of DM or development of new DM after the start of steroid treatment [63].

Exocrine dysfunction of AIP patients may be attributed to loss of acinar cells caused by massive infiltration of inflammatory cells and fibrosis and by disturbance of pancreatic juice flow due to periductal inflammatory cells and resulting duct narrowing. Endocrine dysfunction of AIP patients may be caused by disturbance of blood flow to islets due to parenchymal fibrosis and by impediment of islets due to spread of inflammation [64].

\section{Extrapancreatic organ involvement}

It has emerged that AIP cases are frequently complicated with various extrapancreatic lesions, such as swelling of lacrimal gland and sialadenitis[65], pulmonary hilar lymph nodes swelling [49], sclerosing cholangitis [66, 67], 
Fig. 7 Histopathological findings of AIP. The H\&E staining (a) of the pancreas specimen shows characteristic findings of lymphoplasmacytic sclerosing pancreatitis (LPSP), showing "storiform fibrosis" with massive infiltration of plasma cells and lymphocytes. Immunohistochemistry for IgG4 on the section adjacent to a demonstrates presence of numerous IgG4-positive plasma cells
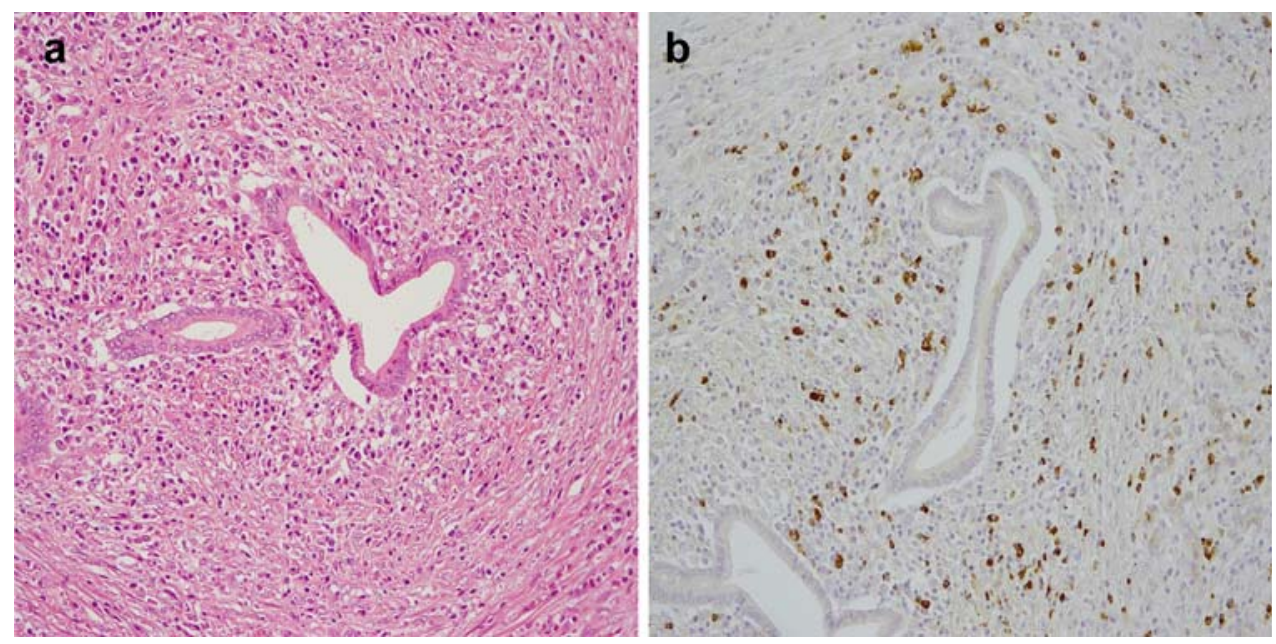

retroperitoneal fibrosis [68], tubulointerstitial nephritis [69, 70] and interstitial pneumonitis [71, 72]. Other lesions reported include hypophysitis [73], chronic thyroiditis [54], pseudotumor of the liver [74, 75], gastric ulcer [76], prostitis [77], Schönlein-Henoch purpura and autoimmune thrombocytopenia [78]. It is unknown whether all of them are real complications of AIP. Representative extrapancreatic lesions have been reported as showing pathological findings similar to the pancreas, including massive lymphoplasmacytic infiltration and fibrosis, obliterating phlebitis and presence of prominent IgG4 positive plasma cells $[8,15]$. AIP patients with multiple extrapancreatic lesions have higher levels of serum IgG4 than those with pancreatic involvement alone, suggesting higher activity in the former [79]. Since AIP is characterized by elevation of serum IgG4 and appearance of numerous IgG4 positive plasma cells in various organs, Kamisawa et al. [15-17, 65] proposed the concept of "IgG4-related sclerosing disease" in which pancreatitis is a manifestation of systemic disease. Recently, some patients have been reported with periarteritis or pseudotumor of the breast or the lung, but without showing abnormal findings in the pancreas [80-83]. These patients were characterized by high serum IgG4 concentrations and numerous infiltrating IgG4-positive plasma cells in the involved lesions, suggesting that IgG4-related systemic disease may occur preceding to or in the absence of pancreatitis.

Complications of AIP such as sclerosing sialadenitis, sclerosing cholangitis, pulmonary lymph node swelling, interstitial fibrosis and pseudotumors resemble Sjögren's syndrome, PSC, sarcoidosis, idiopathic pulmonary fibrosis and malignant tumors, respectively. To confirm the diagnosis, histopathological evidence of LPSP-like findings and presence of numerous IgG4 positive plasma cells are required. Differential diagnosis can be made clinically by various serological findings and fair response to steroids in AIP. In addition, there is a tendency for sclerosing sialadenitis with AIP to involve submandibular glands symmetrically, to show infrequent dry eye symptoms, and to lack SS-A and SS-B antibodies compared with Sjögren's syndrome. These clinical features suggest a resemblance to Mikulicz disease. Concerning sclerosing cholangitis with AIP, Nakazawa et al. $[84,85]$ reported that it shows some differences in the cholangiographic findings from PSC.

\section{Mechanism}

Autoimmune pancreatitis is unique as an autoimmune disease in its predominance in elderly males and its prompt response to steroids. So far, there is no report of familial aggregation of AIP, suggesting a multifactorial genetic disease. Kawa et al. [86] investigated the HLA gene and reported that the frequency of HLA DRB $1 * 0405$ DQB1*0401 haplotype was significantly higher in AIP patients than in healthy subjects and in patients with chronic calcifying pancreatitis. The relation between the HLA gene and AIP was confirmed by comprehensive mass-screening using microsatellite markers [87]. The results suggested that presentation of some peptide antigens to $\mathrm{T}$ cells through HLA DRB $1 * 0405$ or HLA DQB $1 * 0401$ molecules may trigger the development of the disease.

A number of autoimmune diseases are caused by failure of peripheral immune tolerance, where regulatory $\mathrm{T}$ cells $\left(\mathrm{CD} 25^{\text {high }} \mathrm{CCD} 4^{+} \mathrm{T}\right.$ cells) play important suppressive roles on self-reactive $\mathrm{T}$ cells, to prevent the development of organ-specific autoimmune diseases. It is reported that the number of regulatory $\mathrm{T}$ cells increases in AIP patients and is correlated with serum IgG4 level, while the number of naïve regulatory $\mathrm{T}$ cells decreases [88].

Autoimmune pancreatitis patients in the active phase sometimes show low levels of serum complements, suggesting organ injury through complement activation. There 
are three pathways for activation of complements: classical, alternative and mannose binding lectin (MBL) pathways. A lack of IgG4 binding capacity to $\mathrm{C} 1 \mathrm{q}$, low $\mathrm{C} 4$ and normal MBL level in serum rules out direct relevance of $\mathrm{IgG} 4$ or activation of alternative and MBL pathways. In the active phase of AIP, the value of IgG4 type immune complex increases in the sera; patients who have higher values of immune complex show significantly higher IgG1, low $\mathrm{C} 4$ and a tendency of low C3 level [89]. This means complement activation through IgG1-triggering classical pathway is more likely to be involved in the pathogenesis.

Uchida et al. [90] skillfully created a model mimicking AIP. They used a well-established mouse model of autoimmune gastritis which is created by removal of thymus at 3 days after birth. When these mice were immunized with lactoferrin (LF) or carbonic anhydrase II at the age of 6 weeks, a remarkable aggregation of lymphocytes was observed around ducts of the pancreas and salivary gland. The finding appeared again when $\mathrm{CD}^{+}$splenocytes of these mice were adoptively transferred to nude mice of the same strain but failed to reappear by the adoptive transfer of $\mathrm{CD}^{+}$splenocytes. The experiments also showed overexpression of IFN- $\gamma$ in the pancreas and salivary glands of affected mice, suggesting an involvement of Th1 type immune reaction.

\section{Treatment}

According to a recent survey on treatment of AIP by the RCIPD of Japan, $98 \%$ of AIP patients achieve remission by oral prednisolone (PLS) [91]. The value is significantly higher than the patients without steroid therapy, endorsing oral PLS as the standard therapy for AIP.

The RCIPD proposed a guideline for treatment of AIP in 2005 [92]. It recommends biliary drainage for patients with jaundice and control of blood glucose level for those with DM. It recommends administration of oral PSL to patients who do not show any improvement of symptoms such as jaundice, biliary stenosis and abdominal pain, but strictly prohibits facile use of steroids before establishing the diagnosis of AIP. It also calls for reevaluation bearing pancreatic cancer in mind when it cannot be ruled out from the clinical course after initiation of steroids. The recommended initial dose of PSL is $30-40 \mathrm{mg} /$ day. After administration of the initial dose for $2-4$ weeks, it is to be reduced gradually, depending on the improvement of clinical signs, to the maintenance dose within roughly 2-3 months. After achievement of remission, maintenance therapy with oral PSL at a dose of $2.5-5 \mathrm{mg}$ /day is principally followed (Fig. 8). Although it was not certain at that time how long the maintenance therapy should be continued, the guideline recommends stopping steroids after a certain period (6-12 months) and carefully considering the possibility of recurrence when following up with patients.

Recently, the RCIPD added some items to the guidelines based on the results of an inquiry into AIP patients with jaundice in 17 high volume centers in Japan [93]. For the initial treatment of AIP patients with jaundice, the revised guideline recommends drainage of the bile duct in cases of biliary infection. Without infection, biliary drainage is not essential but a stent-placement is recommended when ERCP is performed for diagnosis of AIP. On the other hand, from the data of time and dose of PSL at recurrence, the revised guideline recommends PSL at a dose of 5.0$7.5 \mathrm{mg} / \mathrm{day}$ for up to 3 years for maintenance therapy (Fig. 8). The study also suggested that swelling of more than $1 / 3$ of the pancreas, uptake of Ga to extrapancreatic organs on Ga scintigraphy and sclerosing cholangitis in any part other than the lower common bile duct are risk factors of recurrence.

\section{Issues to be settled in the future}

\section{Asian diagnostic criteria and HISORt criteria}

There have been several reports of AIP from Korea [19, 26, 94]. Clinicopathological features of Korean cases show that AIP in Korea is almost identical to AIP in Japan; both centered on LPSP. Kim et al. [26] of Asan Medical Center proposed their own clinical criteria of AIP in 2006, which were modified by the Korean Society of Pancreatobiliary Diseases and released as the Korean Criteria for AIP in 2007 (Table 2) [94]. These are comprised of 4 items: Criterion I: Imaging, Criterion II: Serology, Criterion III: Histopathology of pancreas/extrapancreatic lesions and Criterion IV: Response to steroids. According to the criteria, the diagnosis of AIP is established when Criterion I and any of II-IV are confirmed or when the full spectrum of LPSP as well as infiltration of abundant IgG4-positive cells are observed in pancreatic resection specimens. Major differences from the Japanese Clinical Criteria of AIP 2006 are the following [12, 13, 95-97]. First, the Korean criteria allow employment of MRCP for judgment of MPD narrowing. Second, they use only serum IgG and IgG4 for serological criterion and excludes $\gamma$-globulin, which was adopted in the Japanese criteria. Third, the Korean criteria state that the presence of abundant IgG4-positive plasma cells in lesions can be, by itself, a basis for the diagnosis of AIP. Fourth, they included pathological findings of extrapancreatic lesions in the criteria of AIP. Finally and most importantly, the criteria permit diagnostic use of steroids and place it in parallel to the serology or histopathology criterion, an idea which strictly contradicts the stance of 


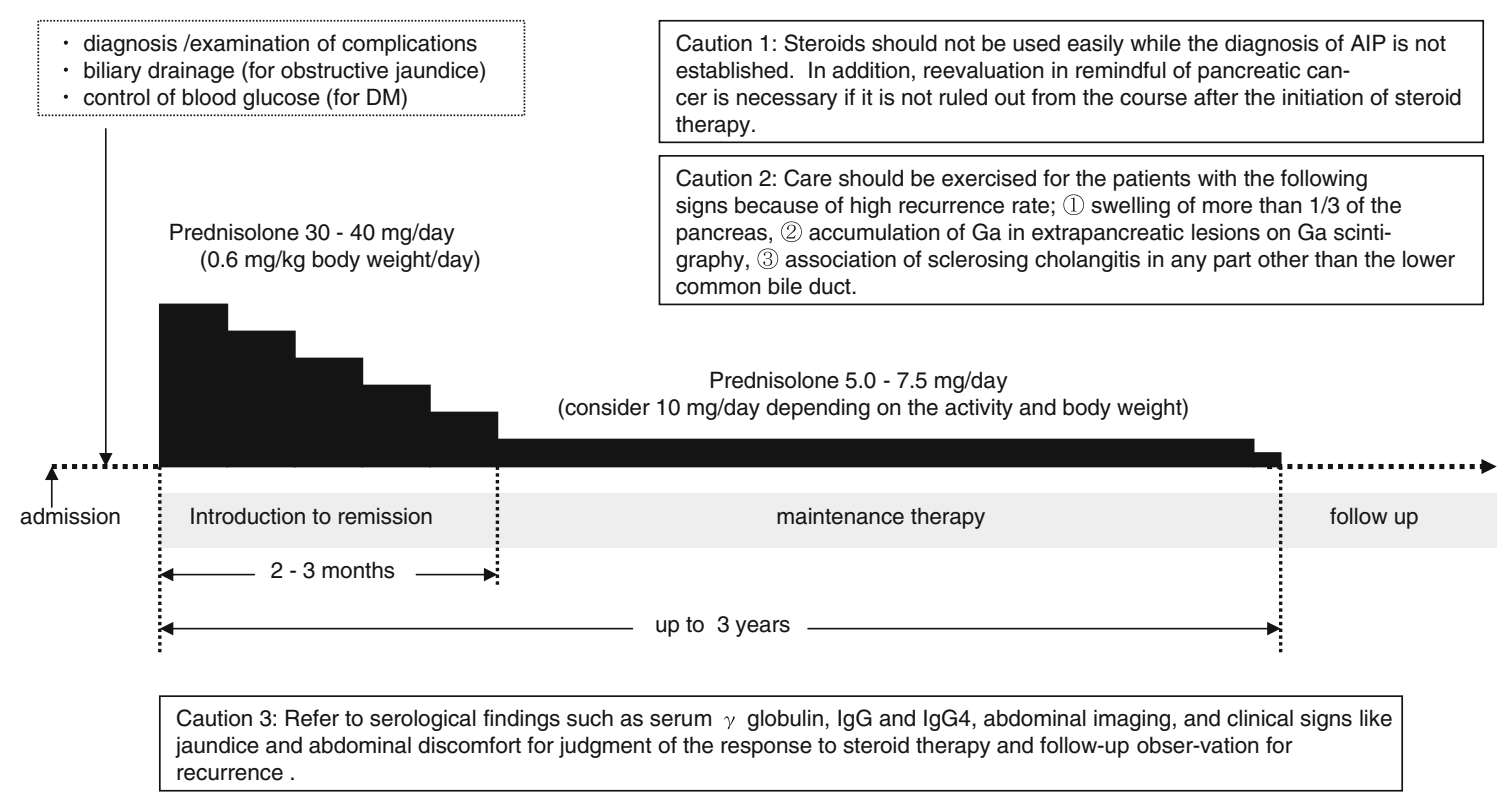

Fig. 8 Schematic drawing of the steroid therapy for AIP recommended by the RCIPD in Japan. Quotation from the reference \#97

Japanese researchers who have been cautious about facile use of steroids due to misgivings that they may delay surgical treatment if the correct diagnosis were to turn out to be pancreatic cancer.

To bridge the gap, Japanese and Korean AIP experts held three meetings in 2007 and 2008 to discuss the consensus criteria of AIP [98-100]. Concerning the use of MRCP in place of ERCP, both sides agreed to understand ERCP as an essential imaging modality due to the currently unsatisfactory resolution of MRI in visualizing the narrowed MPD in AIP patients. The elimination of $\gamma$-globulin was accepted by Japanese researchers because of its low sensitivity. Korean experts admitted the Japanese pathologists' claim of the appearance of IgG4 positive plasma cells not only in the lesions of AIP but in other pathological lesions such as pancreatic cancer, so that the sole pathological basis on IgG4 positive plasma cells was abandoned. The opinion that the diagnosis of AIP should be made from the viewpoint of the pancreas and not by extrapancreatic lesions was preferred. Both sides agreed that LPSP, if confirmed in surgical resection of specimens, can establish the diagnosis of AIP. In addition, both sides agreed to employ histological criteria based on biopsy specimens of the pancreas when the findings are defined as lymphoplasmacytic infiltration in fibrosis, common with abundant IgG4-positive cell infiltrations. Finally, diagnostic trial of steroid therapy was adopted as an option. It was agreed that diagnostic trials of steroid therapy could be conducted carefully by pancreatologists and only in patients fulfilling the imaging findings compatible with AIP alone with negative workup results for pancreatobiliary cancer. Japanese and Korean experts confirmed the agreements and proposed the consensus criteria as the Asian Diagnostic Criteria for AIP in 2008 (Table 3) [100].

Shortly after the Asian Diagnostic Criteria were published, an international conference was held in Seoul to discuss the current view on AIP among experts from Japan, Korea, US and several European countries (AIP Summit 2008). A major focus was the difference between the Asian Diagnostic Criteria and the HISORt criteria proposed by Chari et al. [27] of the Mayo Clinic (Table 4). The HISORt criteria consist of 5 items; Histology, Pancreatic imaging, Serology, Other organ involvement and Response to steroid therapy. The HISORt criteria place much importance on histological findings and allow presence of IgG4 positive cells in involved lesions as a sole pathological basis for the diagnosis. In addition, the criteria classify the findings of imaging into typical and others, and do not specify the modality for judgment of MPD narrowing. The criteria use only IgG4 as the factor of serological findings and make diagnosis possible by extrapancreatic lesions if they respond to steroids or show infiltration of IgG4 positive cells. Although comprehensive criteria were not achieved at the conference, both Asian and Western experts agreed to continue working together to find international consensus criteria of AIP based on the common recognition that AIP is, at present, defined pathologically as LPSP. 
Table 2 Korean criteria for AIP

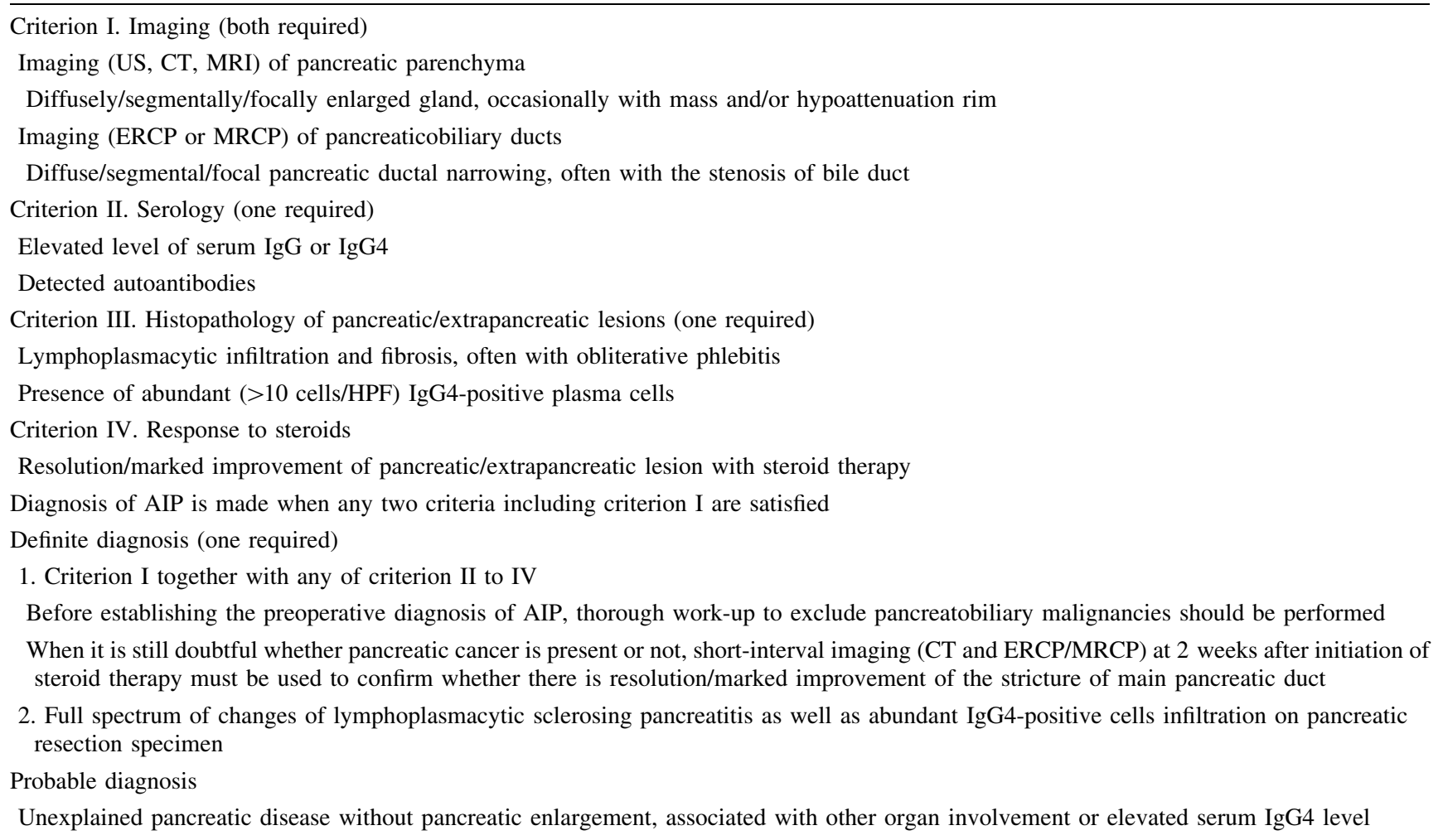

Table 3 Asian diagnostic criteria for AIP

Criterion I. Imaging (both required)

1. Imaging of pancreatic parenchyma

Diffusely/segmentally/focally enlarged gland, occasionally with mass and/or hypoattenuation rim

2. Imaging of pancreaticobiliary ducts

Diffuse/segmental/focal pancreatic ductal narrowing, often with the stenosis of bile duct

Criterion II. Serology (one required)

1. Elevated level of serum $\mathrm{IgG}$ or $\mathrm{IgG} 4$

2. Detected autoantibodies

Criterion III. Histopathology of pancreatic biopsy lesion

Lymphoplasmacytic infiltration in fibrosis, common with abundant IgG4-positive plasma cell infiltration AIP should be diagnosed when criterion I and one of the other two above criteria are satisfied, or when the histology shows the presence of lymphoplasmacytic sclerosing pancreatitis in the resected pancreas

Optional criterion: response to steroid therapy

Diagnostic trials of steroid therapy could be conducted carefully by pancreatologists and only in patients fulfilling criterion I alone with negative work-up results for pancreatobiliary cancer

\section{LPSP and IDCP/GEL}

At the AIP Summit 2008, Klöppel showed typical pathological findings of AIP with GEL [23-25]. It is reported that AIP with GEL has different clinical characteristics from AIP with LPSP, such as occurrence at younger age, lack of serum IgG4 elevation and frequent complication of inflammatory bowel diseases. Therefore, it may constitute another group of pancreatitis developing on the grounds of immunological disorders. In Japan, AIP with LPSP is predominant and only a few cases of IDCP or GEL have been known. There are two important issues. One is that there are no clinical criteria for IDCP or GEL and the definition is based solely on pathological findings. Since it is still hard to obtain large enough specimens by needle aspiration biopsy, confirmation of IDCP or GEL is clinically very difficult. 
Table 4 Diagnostic criteria for AIP (the HISORt criteria, Mayo Clinic)

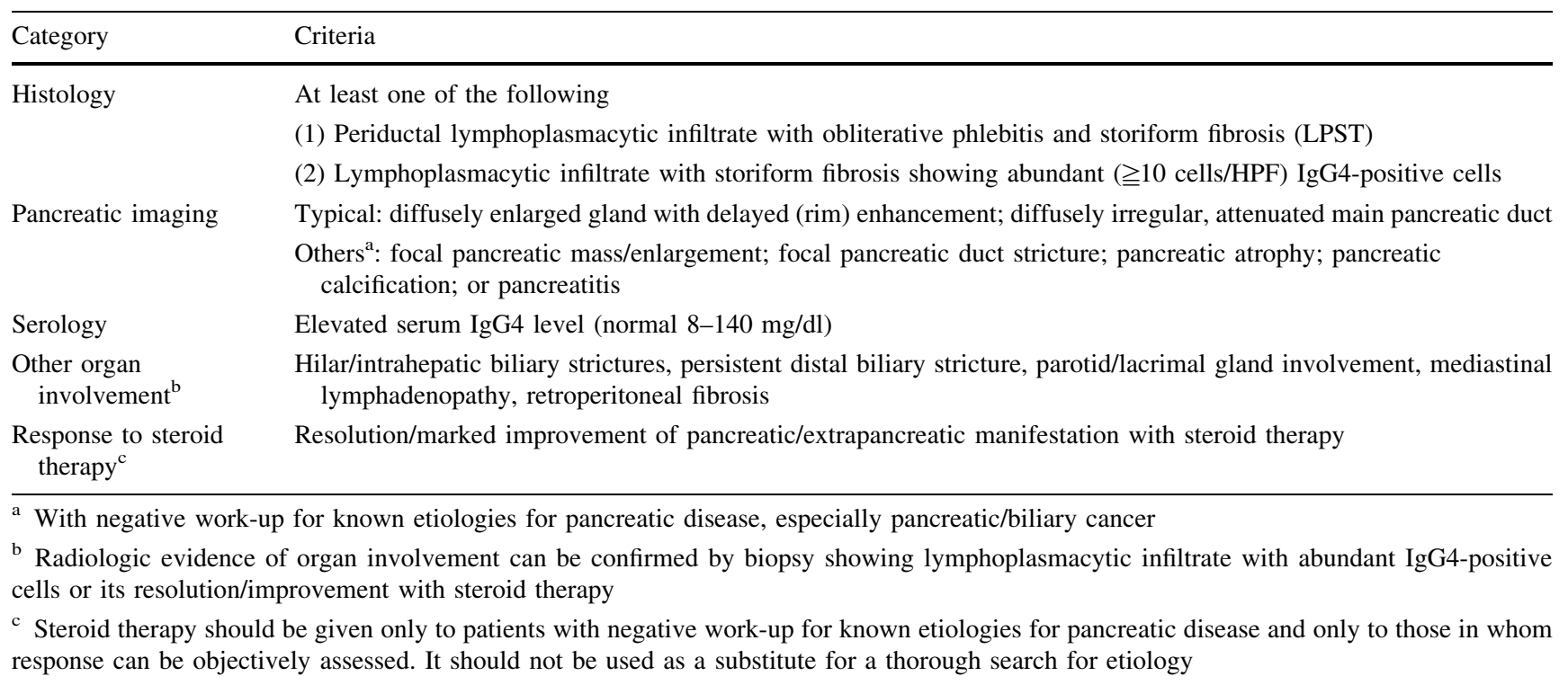

The other is insufficient information regarding AIP from Western countries, especially concerning AIP with LPSP, probably due to a low recognition of this disease. This may give rise to a misunderstanding regarding the true extent of AIP in Western countries. It is important that experts of Asian and Western countries meet together and discuss regional and racial difference in the pathology and clinical features of AIP.

\section{Consensus of steroid treatment}

Consensus has not been formed concerning steroid therapy of AIP. There are two ideas. One places importance on steroid maintenance therapy after introduction of remission in order to prevent recurrence, while the other recommends early suspension of steroids but restarts oral steroids when AIP recurs. Japanese and Korean experts recommend the former and discuss the best uses of steroids for the prevention of recurrence [26, 92, 93]. Chari et al. [27] of the Mayo clinic recommend starting oral PSL at a dose of $40 \mathrm{mg} /$ day and continuing it for 4 weeks as the initial treatment, followed by a reduction of $5 \mathrm{mg}$ each week to gain remission within 11 weeks, and thereafter stopping steroid administration. The RCIPD of Japan examined 96 AIP patients who were followed up for more than 2 years after initiation of steroid therapy [93]. The results revealed that recurrence appeared in 38 of 96 patients (39.6\%), 19 in the pancreas $(50 \%), 11$ in extrapancreatic organs $(29 \%)$ and 8 in both $(21 \%)$. Recurrence appears within three years after the start of steroid therapy and rarely thereafter. The frequency of recurrence was significantly lower in patients treated with PSL at doses of $5.0-7.5 \mathrm{mg} /$ day for maintenance compared with those maintained at doses less than $2.5 \mathrm{mg} /$ day (26.5 vs. $48.1 \%, P=0.045)$. The overall recurrence rate was $53.8 \%$ after the cessation of steroid therapy and it was seen within 1.5 years in most patients $(85.7 \%)$. There are no clear data concerning which method of steroid treatment is preferrable in suppressing recurrence while holding the unfavorable side effects of steroids down, an important consideration as AIP occurrs preferentially in elderly people. A prospective randomized study is necessary to determine the best method of steroid use for treatment of AIP.

The Japanese Clinical Criteria 2006 were inadequate in diagnosing AIP in thpatients who fulfilled the imaging criteria but lacked serological findings unless histological diagnosis was confirmed. However, it is difficult to correctly diagnose of AIP on the basis of the tiny specimens obtained by US- or EUS-guided aspiration biopsy. Indeed, a recent report from Korea shows that transabdominal US-guided pancreatic core biopsy could give a correct diagnosis in only $26 \%$ of AIP patients examined [101]. Some experts recommend the use of an EUS-guided 19-gauge Trucut needle to obtain a larger tissue sample but there are limitations for the use of such large-caliber needles due to technical difficulty and possible risk of complications [102]. Therefore diagnostic use of steroids may be the only way to differentiate AIP with negative serum factors from pancreatic cancer. Japanese experts have been reluctant to approve diagnostic trials of steroid therapy because a certain period of steroid use might miss the best time window for surgery if the correct diagnosis were pancreatobiliary malignant disease. Kim et al. recommended reevaluation by $\mathrm{CT}$ and ERCP/MRCP at 2 weeks after initiation of steroid therapy to evaluate the 
responsiveness in the cases in whom the possibility of pancreatic cancer is not ruled out completely [94]. Now, with agreement between Japanese and Korean experts, diagnostic trials of steroid therapy have been adopted as an optional criterion in the Asian Diagnostic Criteria for AIP [100]. Further study is necessary to clarify the best timing and the best way to evaluate steroid response without causing unfavorable steroid effects, even if reevaluation turns out need of surgical resection for the pancreatic lesion.

\section{Long-term prognosis}

Long-term prognosis of AIP is still unclear. Some reports show an appearance of pancreatic atrophy in $30-40 \%$ of AIP patients and pancreatic stones in 6.5-25\% [103-105]. The appearance of stones is especially high, approximately $50 \%$ in the patients with recurrence. Kawa et al. studied 51 cases of AIP who had been followed up for more than 24 months. They reported that recurrence appeared in $41.2 \%$ and pancreatic stones in $17.6 \%$ of overall patients, $33.3 \%$ in the patients with recurrence and $6.7 \%$ in those without recurrence [105]. This finding suggested repeating recurrence of AIP may lead to formation of pancreatic stones, as is the usual case with chronic pancreatitis.

At present there are reports of 11 AIP cases complicated with pancreatic cancer, 5 cases at the diagnosis of AIP and 6 cases at 3-5 years after initiation of steroid therapy [104, 106-108]. Iida et al. [106] pointed out a unique tendency for the site of occupancy: the cancer occurred in the body or tail of the pancreas in 9 of 11 cases, contrasting with dominant occurrence in the head of the pancreas generally. They called attention to a difference in the pathogenesis from ordinary ductal cancer and suggested relevance of a repeating and sustaining inflammation within the pancreas and/or immune suppression due to long-standing steroid use. Eight of 11 cases (72.7\%) showed associated elevation of serum CA19-9 when cancer developed. Iida et al. [106] call attention to the idea that AIP may predispose to pancreatic cancer and recommend to follow up patients carefully by tumor markers and contrast-enhanced CT every 3-6 months for 2-3 years, even after the disappearance of inflammation and cessation of steroid therapy.

\section{References}

1. Yoshida K, Toki F, Takeuchi T, Watanabe S-I, Shiratori K, Hayashi N. Chronic pancreatitis caused by an autoimmune abnormality. Proposal of the concept of autoimmune pancreatitis. Dig Dis Sci. 1995;40:1561-8.

2. Sarles H, Sarles JC, Muratore R, Guien C. Chronic inflammatory sclerosis of the pancreas-an autonomous pancreatic disease? Am J Dig Dis. 1961;6:688-98.
3. Nakano S, Takeda I, Kitamura K, Watahiki H, Iinuma Y, Takenaka M. Vanishing tumor of the abdomen in patient with Sjogren's syndrome. Am J Dig Dis. 1978;23:75s-9s.

4. Montefusco PP, Geiss AC, Bronzo RL, Randall S, Kahn E, Mckinley MJ. Sclerosing cholangitis, chronic pancreatitis, and Sjogren's syndrome: a syndrome complex. Am J Surg. 1984; 14:822-6.

5. Semba D, Morioka Y. A case of primary sclerosing cholangitis associated with chronic pancreatitis and Sjogren syndrome. Jpn J Gastroenterol. 1987;84:2745-9.

6. Shibata T, Hayakawa T, Kondo T, Kitagawa M, Ono H, Sakai Y, et al. A case of chronic pancreatitis associated with Sjogren's syndrome. Jpn J Gastroenterol. 1989;86:960-4.

7. Kiriyama S, Nakano S, Sugiyama K. Chronic pancreatitis associated with Sjogren's syndrome. In: Saito Y, editor. Chronic pancreatitis in Japan. Tokyo: Kokusai-isyo-syuppan; 1991. p. 180-2.

8. Kawaguchi K, Koike M, Tsuruta K, Okamoto A, Tabata I, Fujita N. Lymphoplasmacytic sclerosing pancreatitis with cholangitis. Hum Pathol. 1991;22:387-95.

9. Toki F, Kozu T, Oi I, Nakasako T, Suzuki M, Hanyu F. An unusual type of chronic pancreatitis showing diffuse irregular narrowing of the entire main pancreatic duct on ERCP - a report of four cases. Endoscopy. 1992;24:640.

10. The Criteria Committee for Chronic Pancreatitis of the Japan Pancreas Society. Final report of clinical diagnostic criteria of chronic pancreatitis (in Japanese). Suizo. 1995;10:xxiii-vi.

11. Members of the Criteria Committee for Autoimmune Pancreatitis of the Japan Pancreas Society. Diagnostic criteria for autoimmune pancreatitis by the Japan Pancreas Society (2002) (in Japanese with English abstract). Suizo. 2002;17:585-7.

12. Members of the Autoimmune Pancreatitis Diagnostic Criteria Committee, the Research Committee of Intractable Diseases of the Pancreas supported by the Japanese Ministry of Health, Labor and Welfare, and Members of the Autoimmune Pancreatitis Diagnostic Criteria Committee, the Japan Pancreas Society. Clinical diagnostic criteria of autoimmune pancreatitis 2006 (in Japanese with English abstract). Suizo. 2006;21:395-7.

13. Okazaki K, Kawa S, Kamisawa $T$, Naruse $S$, Tanaka $S$, Nishimori I, et al. Clinical diagnostic criteria of autoimmune pancreatitis: revised proposal. J Gastroenterol. 2006;41:626-31.

14. Hamano H, Kawa S, Horiuchi A, Unno H, Furuya N, Akamatsu $\mathrm{T}$, et al. High serum IgG4 concentrations in patients with sclerosing pancreatitis. N Engl J Med. 2001;344:732-8.

15. Kamisawa T, Nakajima H, Egawa N, Funata N, Tsuruta K, Okamoto A. IgG4-related sclerosing disease incorporating sclerosing pancreatitis, cholangitis, sialadenitis and retroperitoneal fibrosis with lymphadenopathy. Pancreatology. 2006; 6:132-7.

16. Kamisawa T, Okamoto A. Autoimmune pancreatitis; proposal of IgG4-related sclerosing disease. J Gastroenterol. 2006; 41:613-25.

17. Kamisawa T, Funata N, Hayashi Y, Eishi Y, Koike M, Tsuruta $\mathrm{K}$, et al. A new clinicopathological entity of IgG4-related autoimmune disease. J Gastroenterol. 2003;38:982-4.

18. Pearson RK, Longnecker DS, Chari ST, Smyrk TC, Okazaki K, Frulloni L, et al. Controversies in clinical pancreatology. Autoimmune pancreatitis: does it exist? Pancreas. 2003; 27:1-13.

19. Kim K-P, Kim M-H, Song MH, Lee SS, Seo DW, Lee SK. Autoimmune chronic pancreatitis. Am J Gastroenterol. 2004; 99:1605-16.

20. Finkelberg DL, Sahani D, Deshpande V, et al. Autoimmune pancreatitis. N Engl J Med. 2006;355:2670-6.

21. Pickartz T, Mayerle J, Lerch MM. Autoimmune pancreatitis. Nat Clin Pract Gastroenterol Hepatol. 2007;4:314-23. 
22. Song Y, Liu QD, Zhou NX, Zhang WZ, Wang DJ. Diagnosis and management of autoimmune pancreatitis: experience from China. World J Gastroenterol. 2008;14:601-6.

23. Notohara K, Burgart LJ, Yadav D, Chari S, Smyrk TC. Idiopathic chronic pancreatitis with periductal lymphoplasmacytic infiltration. Clinicopathologic features of 35 cases. Am J Surg Pathol. 2003;27:1119-27.

24. Klöppel G, Luttges J, Löhr M, Zamboni G, Longnecker D. Autoimmune pancreatitis: pathological, clinical, and immunological features. Pancreas. 2003;27:14-9.

25. Zamboni G, Lüttges J, Capelli P, Frulloni L, Cavallini G, Pederzoli P, et al. Histopathological features of diagnostic and clinical relevance in autoimmune pancreatitis: a study on 53 resection specimens an d9 biopsy specimens. Virchows Arch. 2004;445:552-63.

26. Kim K-P, Kim M-H, Kim JC, Lee SS, Seo DW, Lee SK. Diagnostic criteria for autoimmune chronic pancreatitis revisited. World J Gastroenterol. 2006;12:2487-96.

27. Chari ST, Smyrk TC, Levy MJ, Topazian MD, Takahashi N, Zhang L, et al. Diagnosis of autoimmune pancreatitis: the Mayo Clinic experience. Clin Gastroenterol Hepatol. 2006;4:1010-6.

28. Nishimori I, Otsuki M. Epidemiological survey of autoimmune pancreatitis and chronic pancreatitis associating with autoimmune diseases in Japan (in Japanese). In: Fiscal 2003 annual report of surveillance study on intractable pancreatic diseases by the RCIPD Japan. 2004. p. 183-7.

29. Nishimori I, Onishi S, Otsuki M. Nationwide survey for autoimmune pancreatitis in Japan (in Japanese with English abstract). Suizo. 2007;22:651-6.

30. Nishimori I, Suda K, Oi I, Ogawa M. Survey of so to call autoimmune pancreatitis-study on the clinical features of steroid-responsive cases (in Japanese). In: Fiscal 2000 annual report of surveillance study on intractable pancreatic diseases by the RCIPD Japan. 2001. p. 72-83.

31. Irie H, Ito T. US, CT and MRI findings of autoimmune pancreatitis based on "clinical diagnostic criteria of autoimmune pancreatitis 2006" (in Japanese with English abstract). Suizo. 2007;22:629-33.

32. Kamisawa T, Tu Y, Nakajima H, Egawa N, Tsuruta K, Okamoto A, et al. Sclerosing cholecystitis associated with autoimmune pancreatitis. World J Gastroenterol. 2006;12:3736-9.

33. Hyodo N, Hyodo T. Ultrasonographic evaluation in patients with autoimmune-related pancreatitis. J Gastroenterol. 2003;38:1155-61.

34. Irie H, Honda H, Baba S, Kuroiwa T, Yoshimitsu K, Tajima T, et al. Autoimmune pancreatitis: CT and MR characteristics. Am J Roentgenol. 1998;170:1323-7.

35. Sahani DV, Kalva SP, Farrell J, Maher MM, Saini S, Mueller PR, et al. Autoimmune pancreatitis: imaging features. Radiology. 2004;233:345-52.

36. Ito T, Nakano I, Koyanagi S, Miyahara T, Migita Y, Ogoshi K, et al. Autoimmune pancreatitis as a new clinical entity. Three cases of autoimmune pancreatitis with effective steroid therapy. Dig Dis Sci. 1997;42:1458-68.

37. Wakabayashi T, Motoo Y, Kojima Y, Makino H, Sawabu N. Chronic pancreatitis with diffuse irregular narrowing of the main pancreatic duct. Dig Dis Sci. 1998;43:2415-25.

38. Horiuchi A, Kawa S, Akamatsu T, Aoki Y, Mukawa K, Furuya $\mathrm{N}$, et al. Characteristic pancreatic duct appearance in autoimmune chronic pancreatitis: a case report and review of the Japanese literature. Am J Gastroenterol. 1998;93:260-3.

39. Hirano K, Shiratori Y, Komatsu Y, Yamamoto N, Sasahira N, Toda N, et al. Involvement of the biliary system in autoimmune pancreatitis: a follow-up study. Clin Gastroenterol Hepatol. 2003;1:453-64.
40. Kamisawa T, Tu Y, Egawa N, Nakajima H, Tsuruta K, Okamoto A. Involvement of pancreatic and bile ducts in autoimmune pancreatitis. World J Gastroenterol. 2006;12:612-4.

41. Okazaki K, Uchida K, Chiba T. Recent concept of autoimmunerelated pancreatitis. J Gastroenterol. 2001;36:293-302.

42. Horiuchi A, Kawa S, Hamano H, Hayama M, Ota H, Kiyosawa K. ERCP features in 27 patients with autoimmune pancreatitis. Gastrointest Endosc. 2002;4:494-9.

43. Nishino T, Toki F, Oyama H, Oi I, Kobayashi M, Takasaki K, et al. Biliary tract involvement in autoimmune pancreatitis. Pancreas. 2005;30:76-82.

44. Nakamoto Y, Sakahara H, Higashi T, Saga T, Sato N, Okazaki $\mathrm{K}$, et al. Autoimmune pancreatitis with F-18 fluoro-2-deoxyD-glucose PET findings. Clin Nucl Med. 1999;24:778-80.

45. Higashi T, Saga T, Nakamoto Y, Ishimori T, Fujimoto K, Doi R, et al. Diagnosis of pancreatic cancer using fluorine-18 fluorodeoxyglucose positron emission tomography (FDG-PET) usefulness and limitations in "clinical reality". Ann Nucl Med. 2003; 17:261-79.

46. Ozaki Y, Oguchi K, Hamano H, Arakura N, Muraki T, Kiyosawa K, et al. Differentiation of autoimmune pancreatitis from suspected pancreatic cancer by fluorine-18 fluorodeoxygludose positron emission tomography. J Gastroenterol. 2008; 43:144-51.

47. Sato M, Okumura T, Shioyama Y, Imura J. Extrapancreatic F-18 FDG accumulation in autoimmune pancreatitis. Ann Nucl Med. 2008;22:215-9.

48. Nakajo M, Jinnouchi S, Fukukura Y, Tanabe H, Tateno R, Nakajo M. The efficacy of whole-body FDG-PET or PET/CT for autoimmune pancreatitis and associated extrapancreatic autoimmune lesions. Eur J Nucl Med Mol Imaging. 2007; 34:2088-95.

49. Saegusa H, Momose M, Kawa S, Hamano H, Ochi Y, Takayama $M$, et al. Hilar and pancreatic gallium-67 accumulation is characteristic feature of autoimmune pancreatitis. Pancreas. 2003;27:20-5.

50. Okazaki K, Chiba T. Autoimmune-related pancreatitis. Gut. 2002;51:1-4.

51. Okazaki K, Uchida K, Ohana M, Nakase H, Uose S, Inai M, et al. Autoimmune-related pancreatitis is associated with autoantibodies and a Th1/Th2-type cellular immune response. Gastroenterology. 2000;118:573-81.

52. Kawa S, Hamano H. Serological markers for the diagnosis of autoimmune pancreatitis (in Japanese with English abstract). Suizo. 2007;22:641-5.

53. Ghazale A, Chari ST, Smyrk TC, Levy MJ, Topazian MD, Takahashi N, et al. Value of serum IgG4 in the diagnosis of autoimmune pancreatitis and in distinguishing it from pancreatic cancer. Am J Gastroenterol. 2007;102:1646-53.

54. Komatsu K, Hamano H, Ochi Y, Takayama M, Muraki T, Yoshizawa K, et al. High prevalence of hypothyroidism in patients with autoimmune pancreatitis. Dig Dis Sci. 2005;50:1052-7.

55. Suda K, Takase M, Fukumura Y, Ogura K, Ueda A, Matsuda T, et al. Histopathologic characteristics of autoimmune pancreatitis based on comparison with chronic pancreatitis. Pancreas. 2005;30:355-8.

56. Suda K, Nishimori I, Takase M, Oi I, Ogawa M. Autoimmune pancreatitis can be classified into early and advanced stages. Pancreas. 2006;33:345-50.

57. Kojima M, Sipos B, Klapper W, Frahm O, Knuth HC, Yanagisawa A, et al. Autoimmune pancreatitis: frequency, IgG4 expression, and clonality of $\mathrm{T}$ and B cells. Am J Surg Pathol. 2007;31:521-8.

58. Deshpande V, Chicano S, Finkelberg D, Selig MK, MinoKenudson M, Brugge WR, et al. Autoimmune pancreatitis: a 
systemic immune complex mediated disease. Am J Surg Pathol. 2006;30:1537-45.

59. Zhang L, Notohara K, Levy MJ, Chari ST, Smyrk TC. IgG4positive plasma cell infiltration in the diagnosis of autoimmune pancreatitis. Mod Pathol. 2007;20:23-8.

60. Ectors N, Maillet B, Aerts R, Geboes K, Donner A, Borchard F, et al. Non-alcoholic duct destructive chronic pancreatitis. Gut. 1997;41:263-8.

61. Kwon S, Kim M-H, Choi EK. The diagnostic criteria for autoimmune chronic pancreatitis. It is time to make a consensus. Pancreas. 2007;34:279-86.

62. Nishimori I, Suda K, Oi I, Ogawa M. The survey on the socalled autoimmune pancreatitis-comparison with pancreatic cancer and chronic pancreatitis (in Japanese). In: Fiscal 2001 annual report of surveillance study on intractable pancreatic diseases by the RCIPD Japan. 2002. p. 100-10.

63. Nishimori I, Tamakoshi A, Kawa S, Tanaka S, Takeuchi K, Kamisawa $\mathrm{T}$, et al. Research Committee on Intractable Pancreatic Diseases, the Ministry of Health and Welfare of Japan. Influence of steroid therapy on the course of diabetes mellitus in patients with autoimmune pancreatitis. Findings from a nationwide survey in Japan. Pancreas. 2006;32:244-8.

64. Ito T, Kawabe K, Arita Y, Hisano T, Igarashi H, Funakoshi A, et al. Evaluation of pancreatic endocrine and exocrine function in patients with autoimmune pancreatitis. Pancreas. 2007; 34:254-9.

65. Kamisawa T, Funata N, Hayashi Y, Tsuruta K, Okamoto A, Amemiya K, et al. Close relationship between autoimmune pancreatitis and multifocal fibrosclerosis. Gut. 2003;52:683-7.

66. Erkelens GW, Vleggaar FP, Lesterhuis W, van Buuren HR, van der Werf SD. Sclerosing pancreato-cholangitis responsive to steroid therapy. Lancet. 1999;354:43-4.

67. Nakazawa T, Ohara H, Yamada T, Ando H, Sano H, Kjino S, et al. Atypical primary sclerosing cholangitis cases associated with unusual pancreatitis. Hepatogastoroenterology. 2001;48: 625-30.

68. Hamano H, Kawa S, Ochi Y, Unno H, Shiba N, Wajiki M, et al. Hydronephrosis associated with retroperitoneal fibrosis and sclerosing pancreatitis. Lancet. 2002;359:1403-4.

69. Takeda S, Haratake J, Kasai T, Takaeda C, Takazakura E. IgG4associated idiopathic tubulointerstitial nephritis complicating autoimmune pancreatitis. Nephrol Dial Transplant. 2004;19: 474-6.

70. Uchiyama-Tanaka Y, Mori Y, Kimura T, Sonomura K, Umemura $\mathrm{S}$, Kishimoto $\mathrm{N}$, et al. Acute tubulointerstitial nephritis associated with autoimmune-related pancreatitis. Am J Kid Dis. 2004;43:e18-25.

71. Taniguchi T, Ko M, Seko S, Nishida O, Inoue F, Kobayashi H, et al. Interstitial pneumonia associated with autoimmune pancreatitis. Gut. 2003;52:683-7.

72. Hirano K, Kawabe T, Komatsu Y, Matsubara S, Togawa O, Arizumi T, et al. High-rate pulmonary involvement in autoimmune pancreatitis. Intern Med J. 2006;36:58-61.

73. Taniguchi T, Hamasaki A, Okamoto M. A case of suspected lymphocytic hypophysitis and organizing pneumonia during maintenance therapy for autoimmune pancreatitis associated with autoimmune thrombocytopenia. Endocr J. 2006;53:563-6.

74. Kanno A, Satoh K, Kimura K, Masamune A, Asakura T, Unno $\mathrm{M}$, et al. Autoimmune pancreatitis with hepatic inflammatory pseudotumor. Pancreas. 2005;31:420-3.

75. Zen Y, Harada K, Sasaki M, Sato Y, Tsuneyama K, Haratake J, et al. IgG4-related sclerosing cholangitis with and without hepatic inflammatory pseudotumor, and sclerosing pancreatitisassociated sclerosing cholangitis. Am J Surg Pathol. 2004; 28:1193-203.
76. Kamisawa T, Egawa N, Nakajima H, Tsuruta K, Okamoto A, Hayashi Y, et al. Gastrointestinal findings in patients with autoimmune pancreatitis. Endoscopy. 2005;37:1127-30.

77. Yoshimura Y, Takeda S, Ieki Y, Takazakura E, Koizumi H, Takagawa K. IgG4-associated prostatitis complicating autoimmune pancreatitis. Intern Med. 2006;45:897-901.

78. Ohara H, Nakazawa T, Sano H, Ando T, Okamoto T, Takada H, et al. Systemic extrapancreatic lesions associated with autoimmune pancreatitis. Pancreas. 2005;31:232-7.

79. Hamano H, Arakura N, Muraki T, Ozaki Y, Kiyosawa K, Kawa S. Prevalence and distribution of extrapancreatic lesions complicating autoimmune pancreatitis. J Gastroenterol. 2006;41: 1197-205.

80. Matsumoto Y, Kasashima S, Kawashima A, Sasaki H, Endo M, Kawakami K, et al. A case of multiple immunoglobulin G4related periarteritis: a tumorous lesion of the coronary artery and abdominal aortic aneurysm. Hum Pathol. 2008;39:975-80.

81. Kasashima S, Zen Y, Kawashima A, Konishi K, Sasaki H, Endo $\mathrm{M}$, et al. Inflammatory abdominal aortic aneurysm: close relationship to IgG4-related periaortitis. Am J Surg Pathol. 2008;32:197-204.

82. Zen Y, Kasahara Y, Horita K, Miyayama S, Miura S, Kitagawa S. Inflammatory pseudotumor of the breast in a patient with a high serum IgG4 level. Histologic similarity to sclerosing pancreatitis. Am J Surg Pathol. 2005;29:275-8.

83. Zen Y, Kitagawa S, Minato H, Kurumaya H, Katayanagi K, Masuda $\mathrm{S}$, et al. IgG4-positive plasma cells in inflammatory pseudotumor (plasma cell granuloma) of the lung. Hum Pathol. 2005;36:710-7.

84. Nakazawa T, Ohara H, Sano H. Cholangiography can discriminate sclerosing cholangitis with autoimmune pancreatitis from primary sclerosing cholangitis. Gastrointest Endosc. 2004;60:937-44.

85. Nakazawa T, Ohara H, Sano H, Ando T, Joh T. Schematic classification of sclerosing cholangitis with autoimmune pancreatitis by cholangiography. Pancreas. 2006;32:229.

86. Kawa S, Ota M, Yoshizawa K, Horiuchi A, Hamano H, Ochi Y, et al. HLA DRB $1 * 0405-\mathrm{DQB} 1 * 0401$ haplotype is associated with autoimmune pancreatic in the Japanese population. Gastroenterology. 2002;122:1264-9.

87. Ota KM, Katsuyama Y, Hamano H, Umemura T, Kimura A, Yoshizawa K, et al. Two critical gene (HLA-DRB1 and ABCF1) in the HLA region are associated with the susceptibility to autoimmune pancreatitis. Immunogenetics. 2007;59:45-52.

88. Miyoshi H, Uchida K, Taniguchi T, Yazumi S, Matsushita M, Takaoka $M$, et al. Circulating Naïve and CD4+CD25high regulatory $\mathrm{T}$ cells in patients with autoimmune pancreatitis. Pancreas. 2008;36:133-40.

89. Muraki T, Hamano H, Ochi Y, Komatsu K, Komiyama Y, Arakura $\mathrm{N}$, et al. Autoimmune pancreatitis and complement activation system. Pancreas. 2006;32:16-21.

90. Uchida K, Okazaki K, Nishi T, Uose S, Nakase H, Ohana M, et al. Experimental immune-mediated pancreatitis in neonatally thymectomized mice immunized with carbonic anhydrase II and lactoferrin. Lab Invest. 2002;82:411-24.

91. Nishimori I, Okazaki K, Suda K, Kawa S, Kamisawa T, Tanaka $\mathrm{S}$, et al. Treatment of autoimmune pancreatitis. The consensus on the treatment of autoimmune pancreatitis by The Research Committee of Intractable Diseases of the Pancreas supported by the Ministry of Health, Labor and Welfare of Japan- (in Japanese with English abstract). Suizo. 2005;20:343-8.

92. Nishimori I, Okazaki K, Suda K, Kawa S, Kamisawa T, Tanaka $\mathrm{S}$, et al. The consensus on the treatment of autoimmune pancreatitis-based on the survey on the actual status (in Japanese). In: Fiscal 2004 annual report of surveillance study on intractable pancreatic diseases by the RCIPD Japan. 2005. p. 223-31. 
93. Nishimori I, Otsuki M. Study on the steroid treatment and recurrence of autoimmune pancreatitis (in Japanese). In: Fiscal 2005-2007 synthetic annual report of surveillance study on intractable pancreatic diseases by the RCIPD Japan. 2008. p. 190-201.

94. Choi EK, Kim M-H, Kim JC, Han J, Seo DW, Lee SS, et al. The Japanese diagnostic criteria for autoimmune chronic pancreatitis: is it completely satisfactory? Pancreas. 2006;33:13-9.

95. Choi EK, Kim M-H, Lee TY, Kwon S, Oh H-C, Hwang CY, et al. The sensitivity and specificity of serum immunoglobulin $\mathrm{G}$ and immunoglobulin G4 levels in the diagnosis of autoimmune chronic pancreatitis Korean Experience. Pancreas. 2007; 35:158-63.

96. Kim M-H. Autoimmune pancreatitis. Gut Liver. 2007;1(Suppl 2):60-2.

97. Okazaki K, Uchida K, Matsushita M, Takaoka M. How to diagnose autoimmune pancreatitis by the revised Japanese clinical criteria. J Gastroenterol. 2007;42:32-8.

98. Kamisawa T, Chung JB, Irie H, Nishino T, Ueki T, Takase M, et al. Japan-Korea symposium on autoimmune pancreatitis (KOKURA 2007). Pancreas. 2007;35:281-4.

99. Park SW, Chung JB, Otsuki M, Kim M-H, Lim JH, Kawa S, et al. Conference report: Korea-Japan symposium on autoimmune pancreatitis. Gut Liver. 2008;2:81-7.

100. Otsuki M, Chung JB, Okazaki K, Kim M-H, Kamisawa T, Kawa $\mathrm{S}$, et al. the Research Committee of Intractable Pancreatic Diseases provided by the Ministry of Health, Labour and Welfare of Japan and the Korean Society of Pancreatobiliary Diseases. Asian diagnostic criteria for autoimmune pancreatitis: consensus of the Japan-Korea symposium on autoimmune pancreatitis. J Gastroenterol. 2008;43:403-8.
101. Bang S-J, Kim M-H, Kim DH, Lee TY, Kwon S, Oh H-C, et al. Is pancreatic core biopsy sufficient to diagnose autoimmune chronic pancreatitis? Pancreas. 2008;36:84-9.

102. Levy MJ, Reddy RP, Wiersema MJ, Smyrk TC, Clain JE, Harewood GC et al. EUS-guided trucut biopsy in establishing autoimmune pancreatitis as the cause of obstructive jaundice. Gastrointest Endosc. 2005;61:467-72.

103. Kamisawa T, Yoshiike M, Egawa N, Nakajima H, Tsuruta K, Okamoto A. Treating patients with autoimmune pancreatitis: results from a long-term follow-up study. Pancreatology. 2005;5:234-8.

104. Nishino T, Toki F, Oyama H, Shimizu K, Shiratori K. Longterm outcome of autoimmune pancreatitis after oral prednisolone therapy. Intern Med. 2006;45:497-501.

105. Takayama M, Hamano H, Ochi Y, Saegusa H, Komatsu K, Muraki T, et al. Recurrent attacks of autoimmune pancreatitis result in pancreatic stone formation. Am J Gastroenterol. 2004; 99:932-7.

106. Iida H, Kubota K, Mawatari H, Yoneda M, Goto A, Abe Y, et al. A case of autoimmune pancreatitis developed pancreatic tail cancer (Japanese and English abstract). Suizo. 2008;23:608-14.

107. Inoue H, Miyatani H, Sawada Y, Yoshida Y. A case of pancreas cancer with autoimmune pancreatitis. Pancreas. 2006;33:208-9.

108. Ghazale A, Chari S. Is autoimmune pancreatitis a risk factor for pancreatic cancer. Pancreas. 2007;35:376.

109. Shimosegawa T. Diagnosis and treatment of autoimmune pancreatitis (in Japanese). Nippon Naika Gakkai Zasshi. 2007; 96:146-52. 